\title{
PRODUÇÃO E DESENVOLVIMENTO DE TRÊS CULTIVARES DE ALFACE (Lactuca sativa L.) SUBMETIDAS A ADUBAÇÃO ORGÂNICA
}

\author{
Mário Euclides Pechara da Costa Jaeggi ${ }^{1}$ \\ Julio Cesar Gradice Saluci² \\ Maxwel Rodrigues Nascimento ${ }^{3}$ \\ Rogério Rodrigues Rangel ${ }^{4}$ \\ Samuel Ferreira da Silva ${ }^{5}$ \\ Diego Rogério Ferraz ${ }^{6}$ \\ Rebyson Bissaco Guidinelle ${ }^{7}$ \\ Alex Justino Zacarias ${ }^{8}$ \\ Israel Martins Pereira9 \\ Wallace Luis de Lima $^{10}$
}

\begin{abstract}
Resumo:O objetivo do estudo foi avaliar doses de adubos orgânica no desevolvimento de três cultivares de alface na região Alegre-ES. O experimento foi instalado em delineamento inteiramente casualizado, em esquema fatorial $3 \times 3$, com quatro repetições. Os tratamentos foram três doses de adubação orgânica composto por esterco bovino mais resíduos de gramíneas (1,5; 3,5 e 4,5 $\left.\mathrm{kg} \mathrm{m}^{-2}\right)$ e três cultivares de alface (Lucy brow; Regina e Vanda) apresentando mesmo tempo fenologico. As análises foram realizadas aos 40 dias após transplantio, sendo mensurados as variáveis biométricas diâmetro do caule; comprimento de raiz; massa fresca da parte aérea e massa fresca total. Pelos resultados obtidos a dose de $4,5 \mathrm{~kg} \mathrm{~m}^{-2}$ do composto orgânico proporcionou maior ganho em diâmetro do caule, comprimento de raiz, massa fresca da parte aérea e massa fresca da raiz nas três cultivares de alface utilizadas (Lucy brow, Regina e Vanda). Palavras-chave: Lactuca sativa L.; Compostagem; Resíduo orgânico.
\end{abstract}

\footnotetext{
1 Departamento de Produção Vegetal/Universidade Estadual Norte Fluminense, Brasil. E-mail: mariopechara@hotmail.com.

2 Instituto Federal do Espírito Santo, Brasil. E-mail: juliosaluci@gmail.com.

3 Departamento de Produção Vegetal/Universidade Estadual Norte Fluminense, Brasil. E-mail: maxwel.rn88@gmail.com.

${ }^{4}$ Departamento de Engenharia/Universidade Federal de Lavras, Brasil. E-mail: rogeriorr7@hotmail.com.

5 Departamento de Produção Vegetal/Universidade Federal do Espírito Santo, Brasil. E-mail: samuelfd.silva@yahoo.com.br.

${ }^{6}$ Instituto Federal do Espírito Santo, Brasil. E-mail: diegofvalim@gamil.com.

7 Instituto Federal do Espírito Santo, Brasil. E-mail: rebysonguidinelle@gmail.com.

8 Instituto Federal do Espírito Santo, Brasil. E-mail: alexjustino12@gmail.com.

9 Instituto Federal do Espírito Santo, Brasil. E-mail: israelmartins80@gmail.com.

10 Instituto Federal do Espírito Santo, Brasil. E-mail: wallace@ifes.edu.br.
} 